\title{
Organizarse, trabajar y luchar: políticas sociales focalizadas y la construcción de capacidades colectivas en una organización territorial de Buenos Aires
}

\author{
Cecilia Cross ${ }^{\star}$
}

* Doctora en Ciencias Sociales, investigadora adjunta en el Centro de Estudios e Investigaciones Laborales, Consejo Nacional de Investigaciones Científicas y Técnicas (CONICET), profesora asociada regular en la Universidad Nacional Arturo Jauretche, Buenos Aires, Argentina.

Correo electrónico:

crosscecilia@gmail.com

Recibido: 19 de diciembre de 2013

Aprobado: 3 de mayo de 2014

Cómo citar este artículo: Cross, C. (2014). Organizarse, trabajar y luchar: políticas sociales focalizadas y la construcción de capacidades colectivas en una organización territorial de Buenos Aires. Memorias, 12(21), 55-72. doi: http://dx.doi.org/10.16925/ me.v12i21.858

\begin{abstract}
Resumen
Introducción: el presente artículo analiza el proceso mediante el cual una organización territorial se constituyó en gestora de programas sociales, gubernamentales y no gubernamentales, caracterizados como políticas sociales focalizadas en el período que va de 1998 al 2009. Metodología: se trabaja el diseño interactivo para investigación cualitativa propuesto por Maxwell (1996), combinando estrategias tradicionales del método con procesos de investigación acción participativa. Se realizan y analizan entrevistas, talleres, registros de campo y documentos siguiendo los lineamientos de Glaser y Strauss. Resultados: la productividad política de los procesos de implementación de políticas focalizadas no puede aprehenderse separando tajantemente sociedad civil y Estado, interés y desinterés, lucha por la subsistencia y política. Conclusiones: se cuestionan los enfoques que parten de lo que llamamos la hipótesis del reemplazo, que sostiene que las políticas focalizadas reemplazaron a las universales, precarizando las condiciones de vida y trabajo de sectores previamente integrados a través del empleo. Lo que observamos, en cambio, es que estos programas permitieron la creación de capacidades colectivas en sectores tradicionalmente segregados de los circuitos de distribución de la propiedad transferida.
\end{abstract}

Palabras clave: políticas sociales focalizadas, capacidades colectivas, organizaciones territoriales, Buenos Aires.

Organize, Work and Struggle: Focalized Social Policies and Building Collective Capacities in a Territorial Organization of Buenos Aires

\begin{abstract}
Introduction: This Article analyzes the process through which a territorial organization became a promoter of governmental and nongovernmental social programs, characterized as localized social policies in the period from 1998 to 2009. Methodology: The interactive design for qualitative research as proposed by Maxwell (1996) is used, combining traditional strategies of the method with participative action research processes. Interviews, workshops, field records and documents are created and analyzed in accordance with the guidelines of Glaser and Strauss. Results: The political productivity of implementation processes of localized policies cannot be understood as completely separate from society and the State, interest and lack of interest, the struggle for subsistence and policy. Conclusions: The article questions approaches based on what it refers to as the replacement hypothesis, which maintains that focalized policies have replaced universal ones, making living and working conditions of sectors that had previously been integrated through employment precarious. What we see, instead, is that these programs facilitated the creation of collective capacities in sectors traditionally segregated from the distribution of transferred property.
\end{abstract}

Keywords: focalized social policies, collective capacities, territorial organizations, Buenos Aires.

Organizar-se, trabalhar e lutar: políticas sociais focalizadas e a construção de capacidades coletivas numa organização territorial de Buenos Aires

\section{Resumo}

Introdução: o presente artigo analisa o processo pelo qual uma organização territorial se constituiu em gestora de programas sociais, governamentais e não governamentais, caracterizados como políticas sociais focalizadas no período que vai de 1998 a 2009. Metodologia: trabalha-se o desenho interativo para pesquisa qualitativa proposto por Maxwell (1996), que combina estratégias tradicionais do método com processos de pesquisa de ação participativa. Realizam e analisam-se entrevistas, oficinas, registros de campo e documentos que seguem os lineamentos de Glaser e Strauss. Resultados: a produtividade política dos processos de implementação de políticas focalizadas não pode ser apreendida separando contundentemente sociedade civil e Estado, interesse e desinteresse, luta pela sobrevivência e política. Conclusões: questionam-se os enfoques que partem do que chamamos a hipótese da substituição, que sustenta que as políticas focalizadas substituíram as universais tornando precárias as condições de vida e trabalho de setores previamente integrados pelo emprego. Em compensação, observamos que esses programas permitiram a criação de capacidades coletivas em setores tradicionalmente separados dos circuitos de distribuição da propriedade transferida.

Palavras-chave: políticas sociais focalizadas, capacidades coletivas, organizações territoriais, Buenos Aires. 


\section{Introducción ${ }^{1}$}

La implementación de programas sociales que se definen como orientados al desarrollo local a lo largo de las últimas décadas ha dado lugar a la consolidación de organizaciones en las grandes ciudades argentinas y sus periferias, cuyas actividades principales consisten en la gestión de dichos programas. Algunas de ellas fueron consolidadas en procesos de tomas de tierra ${ }^{2}$ en los ochenta y noventa; otras fueron impulsadas por partidos políticos, organismos gubernamentales y no gubernamentales. Cada una de estas ostenta diferentes particularidades vinculadas a su historia, pero en general se las puede definir por tres características básicas: la primera es que se referencian en un barrio popular, usualmente una villa o un asentamiento; ${ }^{3}$ la segunda es que sus líderes residen en el barrio, y la tercera es que las actividades que se realizan cotidianamente, llamadas comunitarias, se vinculan directa o indirectamente con la implementación de los programas sociales: preparación y distribución de alimentos secos y frescos, gestión de subsidios, registro de la situación sanitaria de los hogares, coordinación de actividades educativas y culturales, entre otras.

\footnotetext{
1 Este artículo presenta resultados de una investigación comenzada en 2001 en el proyecto de investigación ріст 2295/12 "Disputas por las formas de regulación del trabajo en establecimientos agropecuarios y emprendimientos asociativos en el período 2003-2013" financiado por el Ministerio de Ciencia, Tecnología e Innovación productiva de Argentina.

2 En el presente texto las itálicas señalan categorías nativas,mientras que las comillas se reservan exclusivamente a citas textuales. El concepto toma de tierras define aquí la ocupación de predios baldíos, privados o fiscales, para la edificación de viviendas.

3 Las villas miseria y asentamientos se definen por estar emplazados en terrenos (fiscales o privados) que fueron tomados por los habitantes para construir sus viviendas, sin que medie la autorización estatal formal para tales efectos. Sin embargo, los asentamientos -que comenzaron a proliferar en los ochenta en un proceso alentado y acompañado entonces por las llamadas Organizaciones Eclesiales de Base- se erigen conforme a una planificación de las calles, los espacios públicos, la dimensión de los lotes de terreno, etcétera, que asemejan su apariencia a la de una urbanización regular. Esto permite que, llegado el caso, la regularización catastral sea más factible y que la instalación de las familias en el lugar sea pensada como permanente. En cambio, las villas miseria no reconocen ningún tipo de organización ni planificación centralizada, se asocian a procesos migratorios internos y externos a lo largo de los cuales las personas recién llegadas a la ciudad residen en la villa por un tiempo hasta que logran instalarse, conseguir un empleo, y mejorar sus condiciones de vida. De todos modos, hay que decir que más allá de estas caracterizaciones formales (e ideales) no necesariamente representan lo que se vive cotidianamente en estas urbanizaciones populares en las que las divisiones entre uno y otro tipo no siempre pueden establecerse de manera clara.
}

Desde el 2001 hemos estudiado diversas organizaciones territoriales, según ángulos y enfoques también múltiples. En este artículo se analiza en particular lo ocurrido en una de estas organizaciones territoriales, a la que llamaré Vecinos Unidos (vU), ${ }_{4}^{4}$ la cual se caracteriza por haber sido constituida en un proceso de toma de tierras ocurrido a fines de los noventa. Dicha organización fue conformada en 1998 por residentes de un asentamiento fundado el mismo año en terrenos que circundan el Complejo Ambiental Norte ini de la Coordinación Ecológica Ârea Metropolitana Sociedad del Estado (CEAMSE), situado en el partido bonaerense de General San Martín. Casi desde su formación, ha sido destinataria de programas vinculados a la contención del conflicto, en el contexto de focalización de las políticas sociales iniciada en los años noventa (Álvarez, 2000). En relación con esta cuestión, se distinguen claramente dos etapas: la primera se extiende entre 1998 y el 2004 y en ella se destacan los programas que asignaron planes ${ }^{5}$ y repartieron mercadería. ${ }^{6}$ En el 2004, cuando comienzan a implementarse programas orientados al desarrollo local proponiendo la conformación de cooperativas de trabajo (Freytes y Cross, 2007), a esta organización se le ofreció participar en el diseño, construcción, equipamiento y puesta en marcha de una planta de clasificación de residuos sólidos urbanos que en la actualidad emplea a unas cien personas.

A lo largo de estos años, y en este contexto tan dinámico, la organización se profesionalizó en tres sentidos: 1) muchas personas hicieron de su vínculo su modo de vida, su profesión, entendida como aquella actividad que organiza su cotidianeidad; 2) los equipos técnicos conformados por especialistas en diversas áreas fueron asumiendo un rol cada vez más preponderante en las actividades de la organización, y 3) tuvo lugar una fuerte especialización en la gestión de las actividades. Este artículo se centra en mostrar el proceso que permitió el desarrollo de las capacidades colectivas que dieron lugar a esta transformación como modo de contribuir a una cuestión teórica central que atraviesa los estudios de políticas sociales focalizadas:

\footnotetext{
4 El nombre de la organización, de la oNG Verdey de mis interlo cutores/as en el trabajo de campo son de fantasía, a fin de preservar el compromiso de confidencialidad asumido con ellos/as.

5 Se designa como plan a los subsidios otorgados a personas desocupadas pobres.

6 Se llama de este modo a los artículos de primera necesidad, prin cipalmente alimentos.
} 
¿qué tipo de integración social ofrecen los programas a las poblaciones destinatarias, vulnerables por definición, y cuál es su (in)eficacia en términos de atenuar esa vulnerabilidad? (Mc Neill, 2006; Filgueira, 2014).

Para ello, comenzaremos por exponer brevemente la metodología utilizada, luego introduciremos los debates centrales del campo académico en los que se sitúa esta reflexión, para pasar a presentar posteriormente los aspectos centrales de la vida cotidiana en el territorio estudiado, a fin de contextualizar los programas sociales implementados en la zona. En el apartado siguiente, analizaremos el proceso que permitió a vU consolidarse como organización territorial en el período 1999-2004. Seguidamente, estudiaremos los desafíos que se plantean a partir del 2004 frente a los cambios en la política social, para ofrecer al final algunas notas acerca de la importancia de revisar nuestras suposiciones al momento de estudiar programas sociales focalizados.

\section{Acerca de la producción de los resultados que aquí se presentan}

Desde el comienzo, la investigación ha sido desarrollada desde los supuestos del paradigma interpretativo que nos lleva a analizar el sentido de las prácticas y discursos insertos en el mundo de la vida de los sujetos que las llevan a cabo (Vasilachis de Gialdino, 2009). De allí que la metodología de trabajo ha sido de tipo cualitativo, por lo que el objeto de la investigación no ha sido la constatación de hipótesis teóricas sino la definición de conceptos y categorías a partir de los datos, utilizando el enfoque de la grounded theory (Glaser y Strauss, 1967), para de este modo comprender sentidos y estructuras de significación que sustentan las prácticas observadas (Raymer, 2009). Esto no significa, sin embargo, que la investigación o la presentación de resultados se hayan llevado a cabo con prescindencia de una adecuada revisión de los debates y aportes teóricos de otras indagaciones contemporáneas o previas. Muy por el contrario, la construcción del marco conceptual es lo que permite, en esta tradición investigativa, formular el problema de investigación para señalar los límites y alcances de nuestra indagación y elaborar resultados en diálogo con las interpretaciones vigentes en el campo científico (Snow, Morill y Anderson, 2003).

En cuanto a las técnicas y procedimientos utilizados para el relevamiento de los datos, hemos trabajado con dos enfoques, dentro de los métodos cualitativos, que se han alternado y complementado a lo largo de diez años de trabajo: los estudios cualitativos clásicos y la investigación acción participativa (Gustavsen, 2003). En el contexto inicial, se trabajó con técnicas que pueden clasificarse de acuerdo con la división clásica entre fuentes secundarias y fuentes primarias. Las primeras constaron de referencias bibliográficas y revisión de informes, fundamentalmente los de la Encuesta Permanente de Hogares (EPH) del Instituto Nacional de Estadística y Censos (INDEC) de Argentina o la base del Sistema de Información, Monitoreo y Evaluación de Programas Sociales (sIEMPRo), dependiente del Consejo Nacional de Coordinación de Políticas Sociales de dicho país. Esta información fue triangulada (Cisterna, 2005) con la obtenida a través de las fuentes primarias, principalmente para reconstruir y analizar el proceso de formulación de demandas y establecimiento de prácticas de gestión de programas sociales en las organizaciones territoriales estudiadas.

Dichas fuentes primarias incluyeron la observación de actividades tales como asambleas plenarias, gestión de programas sociales, organización de actividades comunitarias y también de marchas y actos a lo largo de todo el período analizado. Además, entre el 2001 y el 2014, se realizaron 78 entrevistas en profundidad (Taylor y Bogdan, 1996) a personas vinculadas a las organizaciones territoriales estudiadas, algunas de las cuales fueron actualizadas a lo largo del lapso examinado. En tanto este estudio sigue las líneas de la grounded theory, la selección de los(as) entrevistados(as) fue realizada en función de la técnica de muestreo teórico (Glaser y Strauss, 1967). Elegimos entrevistar a personas que ocuparan roles diferentes en las organizaciones estudiadas y que se hubieran integrado en distintos momentos a estos procesos, con variadas condiciones de género y edad y diversas experiencias políticas y laborales. Así mismo, entrevistamos a 14 informantes clave, entre dirigentes políticos y sindicales y funcionarios(as) y trabajadores(as) de la CEAMSE.

A fin de comprender el modo en que se desarrollaron los procesos de conformación de las mencionadas organizaciones y su constitución como gestoras de programas sociales, se analizaron documentos tales como boletines, folletos, discursos, declaraciones, volantes y publicaciones en la Web. Igualmente, estudiamos los principales programas vigentes entre el 2001 y el 2014 y entrevistamos a funcionarios(as) públicos(as) del ámbito nacional, provincial y municipal. Complementariamente, examinamos información periodística de los diarios de mayor circulación en la zona metropo- 
litana de Buenos Aires, es decir, Clarín, La Nación y Página/12, para dar cuenta de los posicionamientos públicos de nuestros(as) entrevistados(as), tanto de quienes estaban vinculados(as) a organizaciones territoriales como de quienes revistaban como funcionarios(as) públicos(as).

En cuanto a los trabajos de investigación acción, estos comenzaron en el 2004 a partir de la demanda efectuada por la organización vu de acuerdo con la cual requerían, frente a la posibilidad de construir una planta social de clasificación de residuos - proceso que analizaremos más adelante-, según sus palabras, "convertir un grupo de quemeros en un colectivo de trabajadores" y no tenían "ni la menor idea de cómo hacerlo". A partir de allí comenzamos a trabajar en conjunto, utilizando los datos previamente recogidos y analizados como preinvestigación para poder avanzar en las etapas subsiguientes, conforme al diseño que propone Ander-Egg (1990). Así, tuvimos cinco procesos de trabajo con la organización (2004-2005; 2007-2009; 2010 2012; 2014 y continúa) que se fueron alternando en torno a tres ejes principales: desarrollar las capacidades de gestión de la organización (Cross y Freytes, 2009a), fortalecer el colectivo de trabajadores(as) de la planta (Freytes, Menéndez, García, Allegrone y Cross, 2009; Cross, 2013) y desarrollar estrategias para mejorar las chances de inserción escolar y laboral de los(as) adolescentes y jóvenes de la zona (Freytes y Cross, 2011). En este marco, se realizaron 74 talleres participativos cuyos registros fueron incorporados al corpus de datos de la investigación.

Dicho corpus de datos fue analizado desde su producción y fue retomado en diferentes momentos; es decir, que no sólo hemos tomado las entrevistas, los registros, las fichas, sino las reflexiones suscitadas en el primer análisis y los subsiguientes, los cuales fueron efectuados desde diversas preguntas y marcos analíticos de referencia. De este modo, hemos podido verificar que no son los datos los que reclaman la aplicación de un cuerpo teórico determinado, a la vez que no cualquier enfoque teórico resiste la confrontación con la base empírica. En este sentido, es posible afirmar que la teoría no está determinada por los datos, ni es posible pensar en una teoría capaz de ordenar el mundo social con independencia de la evidencia empírica sobre la que fue construida. Consideramos que las relaciones de determinación o indeterminación entre teoría y datos deben ser superadas a partir del principio de subdeterminación de las teorías por los datos, en el sentido de que los cuerpos teóricos adecuados para interpretar un complejo de datos son aquellos que permiten construir relaciones entre conceptos y categorías que organicen la base empírica sin forzar o suprimir su complejidad con base en un ejercicio interpretativo en el que se rescate la "sustantividad del mundo" (Schuster, 2002).

En este orden de ideas, consideramos pertinente rescatar la distinción efectuada por Searle (2006) entre la dimensión ontológica y epistemológica de los hechos institucionales, que son los objetos de las ciencias sociales y humanas. De acuerdo con el autor, estos tienen una subjetividad ontológica y una objetividad epistemológica en tanto tienen una existencia que no depende del punto de vista individual, pero no pueden comprenderse por fuera del contrato social que impone el lenguaje, es decir, poseen una existencia social que ha sido intersubjetivamente construida. ${ }^{7}$

En este sentido, el desafío que hemos adoptado ha sido considerar cada testimonio, registro, declaración pública e interpretación académica, propia y ajena, en su contexto de producción, sin sustraernos al desafío de repensarlo en función de los acontecimientos que se sucedieron con posterioridad y los rastros de la experiencia previa de quien habla. En este escenario, consideramos pertinente rescatar la función narrativa tal y como ha sido presentada por Ricœur (2000). En el acto de narrar, se pone de manifiesto el carácter temporal de la experiencia humana, a través del proceso de elaboración de la trama que permite articular un discurso. Al narrar su biografía, las personas seleccionan episodios y establecen conexiones causales, fines y efectos no deseados, otorgando coherencia a la trama que elaboran. No obstante, dicha trama no puede comprenderse por fuera de sus condiciones de elaboración, las cuales involucran no sólo la construcción de una identidad narrativa que posiciona a la personas respecto al mundo (Ricœur, 1996), sino a los intereses que atribuyen a sus interlocutores(as).

Conforme con este enfoque, entonces, al analizar nuestros registros, lo que buscamos reconstruir es la trama de sentidos que se construye en el proceso de implementación de los programas sociales, dando cuenta

$\mathrm{El}$ autor distingue los hechos que son relativos respecto a quienes los experimentan, como las cosquillas y el dolor, y aquellos que son independientes de la experiencia humana, como la gravedad o la fotosíntesis. Los hechos que constituyen el objeto de las ciencias humanas son dependientes de la experiencia humana, pero no relativos en relación con la experiencia individual. A estos últimos los llama hechos institucionales; por ejemplo, un billete de veinte dólares es tal en el marco de una historia y existencia social dada, no puede ser negado su carácter por un individuo aislado, ni puede comprenderse su existencia prescindiendo de la interacción humana. 
además de cómo se transforman las posiciones subjetivas de las personas involucradas en el proceso y los vínculos que entablan mientras llevan a cabo las distintas actividades que imponen dichos programas.

\section{Focalización y construcción de capacidades colectivas}

Tradicionalmente, la literatura distingue programas sociales universales, asociados a la sociedad salarial, y focalizados, vinculados a los procesos de desmantelamiento del Estado protector (Kerstenetzky, 2006; Leuboult, Fischer y Saha, 2014; Danani, 2013; Filgueira, 2014). Los primeros tienen una lógica impersonal porque alcanzan a todos(as) quienes acrediten las condiciones que definen a la población beneficiaria, mientras que los focalizados requieren, además de acreditar los parámetros que definen a los(as) derechohabientes, la conformación de listas que identifiquen fehacientemente a quienes han sido reconocidos como beneficiarios(as). A su vez, las políticas llamadas universales están dirigidas a empleados(as) en relación de dependencia, mientras que las focalizadas definen a sus destinatarios(as) como vulnerables. Este cambio se ha fundamentado en el hecho de que las políticas universales difícilmente llegaban a los sectores con mayor déficit de integración social, como campesinos(as), mujeres, trabajadores(as) informales (Kenworthy, 2011). Los(as) críticos(as) de la focalización, en cambio, concluyen que este tipo de estrategias son ineficaces en la reparación de los lazos sociales de los sectores vulnerables en al menos dos aspectos: por un lado, sus exiguas prestaciones difícilmente alcanzan a revertir la pobreza de la población destinaria; por otro, al seleccionar una a una a las personas destinarias tomando en cuenta rasgos personalísimos (género, edad, experiencia laboral, cantidad de hijos/as a cargo, estado de salud, etcétera), se termina esencializando la vulnerabilidad social de los(as) derechohabientes y haciéndolos(as) foco de toda suerte de estigmatizaciones (Baker, 2005; Cross, 2013).

Este debate se ha instalado en América Latina desde mediados de los años noventa, cuando comenzaron los procesos de reforma del Estado inspirados en el Consenso de Washington, y se mantienen vigentes hasta la actualidad (Candia, 1998; Andrenacci y Repetto, 2006; Filgueira, 2014). Por eso, en Argentina la mayoría de los análisis colocaron los cambios operados en las políticas sociales como parte de un proceso de transformación del rol del estado (Álvarez, 2000) que adquirió la forma de focalización residual en un esquema de justicia social mercadocéntrica, que habría deparado un deterioro notable en las condiciones de vida y trabajo de los sectores subalternos (Hintze, 2007; Danani, 2013).

A pesar de la amplia coincidencia en este punto, podemos encontrar matices que, por razones de economía argumentativa, podemos dividir en dos líneas de tratamiento: las que miran este cambio desde el punto de vista de la población destinataria y las que enfatizan el accionar estatal. En el primer grupo se destaca Merklen (2000, 2005), que piensa estos cambios en cuanto a desafiliación ${ }^{8}$ (Castel, 1997), sosteniendo que a partir del cambio en las políticas sociales en los noventa, los sectores populares bonaerenses habrían transformado el modo en que se relacionan con el Estado. Según entiende, mientras los(as) trabajadores(as) estuvieron integrados(as) a través del empleo, se habrían comportado de acuerdo con la "lógica del agricultor", que supone planificar la vida sobre "la base del ritmo de los ciclos naturales", con cierta previsibilidad y un arraigo territorial definido. Luego, al perder sus empleos, habrían adoptado una "lógica del cazador" de recursos, subsidios y prestaciones en un "recorrido incesante por las instituciones" estatales (Merklen, 2000, p. 81). Asimismo, interpreta que la "lógica del agricultor" a la "lógica del cazador" implicó "el pasaje del ámbito sindical orientado a los derechos del trabajador, al territorial identificado con las necesidades del pobre" (p. 34). En esta lectura, necesidad y política se oponen desde una mirada neokantiana, que asume la distinción nítida entre Estado y sociedad civil, lógicas de interés y del desinterés, política y subsistencia (Cross, 2013).

En el segundo grupo, encontramos una serie de trabajos que han puesto el acento en la pérdida de derechos sociales que suponen las políticas que exigen contraprestación laboral o promueven formas no asalariadas de inserción en el trabajo, como la conformación de cooperativas. Muchos de los programas sociales

8 El concepto de desafiliación, desarrollado por Castel para pensar la situación francesa, supone que, frente al resquebrajamiento del estado benefactor, los/as trabajadores/as desocupados/as, al perder la posibilidad de participar de los circuitos de distribución de propiedad transferida, han perdido los soportes que les permiten afirmarse como individuos -racionales, pensantes, hábiles para posicionarse en el espacio públicoy se convierten en seres vulnerables, no sólo porque carecen de recursos materiales, sino también por su incapacidad de articular colectivamente sus intereses. 
diseñados desde mediados de los noventa, ${ }^{9}$ en efecto, requieren la realización de prestaciones pseudolaborales en actividades tales como obras públicas, tareas de cuidado de niños y ancianos, apoyo escolar, elaboración y distribución de alimentos adquiridos con fondos públicos, entre otras, a cambio de un pago monetario exiguo y temporalmente acotado que en nada se parece a la institución del salario, no sólo por su escaso monto, sino porque prácticamente no reconoce derechos sociales. Por su parte, las cooperativas de trabajo impulsadas desde políticas sociales están muy lejos de ofrecer condiciones laborales asimilables a las del trabajo asalariado (Maldovan, 2011; Cross, 2013). Estos enfoques suelen pensar la implementación como una relación lineal y unilateral entre el Estado como actor homogéneo y la población destinataria, considerando cualquier intermediación, como la de las organizaciones sociales, religiosas o políticas, como fuente de lazos sociales espurios como el clientelismo político (Vilas, 1997; Grassi, 2003; Andrenacci y Repetto, 2006; Hintze, 2007; Danani, 2013).

A pesar de sus diferencias, se observa que estos dos enfoques coinciden en subrayar la ineficacia de estos programas respecto a la (re)construcción de lazos sociales, pero también es posible observar que ambos parten explícita o implícitamente del supuesto de que la población destinataria de estos programas era la misma que accedía a participar de la propiedad transferida a través del salario. Estos dos supuestos - pensar la implementación de programas sociales como una relación lineal y asumir que la población destinataria de dichos programas es la misma que antes tenía empleo-configuran lo que hemos llamado hipótesis del reemplazo. De acuerdo con esta hipótesis, las políticas focalizadas han venido a reemplazar a las universales deteriorando (precarizando) las condiciones de vida y trabajo de los sectores subalternos: cambiando un salario por un subsidio mínimo, un trabajo calificado y calificante de jornada completa por una contraprestación pseudolaboral de media jornada, el derecho a participar de los beneficios de la propiedad transferida a la necesidad de recorrer instituciones en busca de asistencia, etcétera.

Sin embargo, esta hipótesis difícilmente puede explicar la trayectoria de muchos(as) de los(as) bene-

\footnotetext{
9 Nos referimos por ejemplo a los programas Trabajar, en sus tres versiones, Jefes y Jefas de Hogar Desocupados y Argentina Trabaja del Gobierno nacional, y Barrios Bonaerense y Programas de Empleo Comunitario (PEC) de la Provincia de Buenos Aires, entre otros (Freytes Frey y Cross, 2007; Cross y Freytes Frey 2009b; Danani, 2013)
}

ficiarios(as) de estos programas, la mayor parte de ellos(as) habituados(as) por generaciones al trabajo informal, no registrado y hasta ilegal, ${ }^{10}$ para quienes la inclusión en estos programas ha sido la primera ocasión de recibir ayuda parte del Estado (Cross, 2013). A su vez, el problema de esta hipótesis es que omite una parte central de la historia, al no preguntarse cuáles fueron las condiciones de posibilidad para el cambio en el modelo de intervención. Mientras la ayuda social fue asignada en función de parámetros impersonales, las instituciones estatales se bastaron a sí mismas para gestionarlas, aunque hay que decir que las empresas empleadoras y los sindicatos tuvieron un papel importante en la vehiculización de los recursos, pero desde que su implementación requirió de la identificación fehaciente de las personas (de ahí la focalización) fue necesario desarrollar nuevos dispositivos que permitieran alcanzar, circunscribir y controlar a los(as) destinatarios(as), que muchas veces fueron creados desde y por integrantes de las poblaciones beneficiarias.

Estas prácticas no pueden aprehenderse desde la hipótesis de la desafiliación ni considerar la implementación de políticas sociales como un proceso lineal o unidireccional. Por eso proponemos el concepto de $\mathrm{ca}$ pacidades colectivas desarrollado por Ricœur (2006). Este concepto es resultado de una lectura del concepto de derecho a capacidades (Sen, 2000), que nos permite pensar la vida cotidiana en los barrios populares en continuidad con procesos sociales mucho más amplios, saliendo de este modo de la trampa que nos ha tendido la propia focalización, la cual consiste en pensar que existe una política popular - o de los pobresdiferente y escindida de la política verdadera, la que no necesita adjetivos y que nada tiene que ver con la lucha por la subsistencia. En esta línea, el concepto de capacidades colectivas se refiere a las posibilidades de hacer que pueden ser reivindicadas (atestadas) por parte de un grupo, en clave de nosotros podemos, nosotros tenemos derecho $a$, mientras sean reconocidas socialmente. De este modo, se recupera el carácter relacional que exige todo proceso de legitimación de derechos y prácticas, sobre todo en lo referido a la gestión de recursos de origen público. A partir de esta conceptualización, podemos redefinir la pregunta central de este texto en función de analizar cuáles fueron las capacidades colectivas que permitieron que vu gestionara programas

10 No olvidemos que hasta el 2002 el reciclaje estaba penado por la ley (Álvarez, 2009). 
sociales entre 1998 y el 2009. De este modo, abordaremos la cuestión central de este texto, es decir, qué tipo de integración social ofrecen estas políticas focalizadas, luego de más de diez años continuos de implementación.

\section{Vida cotidiana en el área Reconquista}

El sistema de disposición de los residuos en la zona metropolitana de Buenos Aires, vigente desde 1977, está basado en el sistema de rellenos sanitarios, centralizado por CEAMSE. Esta sociedad estatal interjurisdiccional, que comprende a la provincia y a la Ciudad de Buenos Aires, ha concesionado los servicios a favor de una Unión Transitoria de Empresas (UTE), conformada por Benito Roggio e Hijos y ORMAS SAICIC. Uno de los principales rellenos es el ubicado en el Complejo Ambiental Norte III, el cual está bordeado por el río Reconquista. Este río le da nombre al área Reconquista, conformada por el conjunto de villas y asentamientos erigidos en torno al relleno.

La mayor parte de los vecindarios que conforman el área Reconquista fueron constituidos a fines de los noventa en procesos de tomas de tierras. Desde todos ellos se puede ver la montaña de basura que se erige al otro lado de la autopista del Buen Ayre. En esta zona los niveles de pobreza e indigencia están por encima de la media del conurbano bonaerense y entre sus habitantes han conformado varias organizaciones territoriales que gestionan programas gubernamentales y no gubernamentales (Álvarez, 2009; Suárez, Brancoli, Neumann y Ruggiero, 2011). Las personas que allí viven señalan que su vida está "marcada por la basura". Edificaron sus hogares en predios en los que durante años funcionaron basurales clandestinos a cielo abierto. El agua que consumen habitualmente está contaminada, porque lo están los suelos y las perforaciones no son suficientemente profundas. El aire también presenta altos niveles de contaminación por las emanaciones tóxicas de los basurales clandestinos, del sumamente contaminado río Reconquista, del propio relleno sanitario y de la autopista que atraviesa la zona (Shammah, 2007). La exposición a estos focos es señalada como la causa de las altas tasas de dermatitis severa, los abortos espontáneos y las malformaciones congénitas, así como de las enfermedades degenerativas e infecciosas que se registran en esta población (Secretaría de Salud de la Municipalidad de Gral. San Martín, 2007).
En esta área, muchos(as) vecinos(as) son queme$\operatorname{ros}(a s)$. Ingresan regularmente al relleno sanitario, al que llaman La Quema, ${ }^{11}$ a procurarse mercadería o materiales ${ }^{12}$ que consumen o venden. Quienes no ingresan tampoco son ajenos(as) a esta práctica: saben dónde conseguir rescates, es decir, insumos o productos que se venden a bajo costo por haber sido recogidos en el relleno sanitario.

Esta práctica ha sido uno de los principales focos de tensión en este territorio. $Y$ es que, a pesar de ser una práctica habitual, el ingreso al relleno sanitario estaba prohibido. Esta contradicción entre práctica y regulación redundaba en una alta exposición de los(as) quemeros(as) a la violencia, tanto entre sí como frente a quienes custodian el predio. El máximo nivel de conflicto en este punto se produjo con la desaparición de Diego Duarte, joven residente del área Reconquista cuya familia denunció que fue enterrado bajo una montaña de basura mientras estaba en el relleno Norte III el 15 de marzo del 2004. La movilización en demanda de justicia protagonizada por Alicia, hermana de Diego, y por distintas organizaciones de la zona, dirigentes de partidos de izquierda y representantes de organismos de derechos humanos, no sólo logró instalar públicamente la convicción de que existió responsabilidad empresarial en su desaparición, sino también la necesidad de sincerar la dependencia de los(as) vecinos(as) respecto al relleno sanitario (Álvarez, 2009).

Este sinceramiento tuvo lugar en un contexto marcado por otros dos conflictos que excedieron la zona estudiada. Primero, la resistencia de grupos vecinales de diferentes localidades del conurbano bonaerense a la apertura de nuevos rellenos sanitarios que permitieran reemplazar los que fueron cerrados por estar saturados o por conflictos planteados por organizaciones ambientalistas o vecinales (Carenzo y Míguez, 2010). Segundo, el rechazo a la excesiva centralización del modelo de gestión actual y su escasa sustentabilidad ecológica y social. CEAMSE fue creado con el propósito de centralizar el tratamiento de la basura, prohibiéndose las actividades de reciclado de materiales.

\footnotetext{
11 El sistema de tratamiento de residuos previo a la constitución de CEAMSE consistía en la incineración de los residuos. Al predio donde estos se transportaban a tal fin se le conocía popularmente como La Quema. A pesar de que el sistema ha cambiado hace más de 30 años, este nombre se sigue aplicando al relleno sanitario.

12 La palabra mercadería refiere a alimentos, en cambio materiales son aquellos objetos que se recogen para ser vendidos.
} 
Los residuos fueron declarados propiedad del Estado y se penalizaron las actividades de clasificación y venta de materiales por parte de particulares. Así se estableció una distinción entre el circuito formal-legal y el informal-ilegal, que incrementó la precariedad en las condiciones de vida y trabajo de los(as) recicladores(as), pero no logró erradicar su actividad como pretendía (Carenzo y Míguez, 2010).

A partir del 2002, en un contexto de fuerte movilización social, el reconocimiento a las actividades de reciclado fue impulsado desde dos vertientes. Por un lado, activistas ambientalistas que buscaron crear conciencia acerca de la necesidad de incorporar el reciclado a la gestión de los residuos como única alternativa sustentable desde el punto de vista ecológico. Por otro, grupos de recicladores(as) que, con el apoyo de expresiones partidarias, estudiantiles y sindicales, lograron defender tanto la relevancia social de sus actividades como su derecho a "ganarse la vida" mediante la recuperación, clasificación y venta de materiales descartados (Maldovan, 2011). El eco político alcanzado por ambas vertientes se plasmó en la legislación a través de la Ley Nacional 25916, la Ley 13592 de la Provincia de Buenos Aires y las Leyes 992 y 1854 de la Ciudad Autónoma de Buenos Aires, que impulsan un modelo social de gestión de los residuos que incorpora como agentes activos a los(as) recuperadores(as) urbanos(as).

Bajo estas circunstancias, en el 2004, CEAMSE acordó con el Estado provincial una serie de medidas destinadas tanto a atender los conflictos locales como a adecuarse al nuevo contexto institucional y político (Cross y Freytes, 2009a). Una de ellas fue la promoción de plantas de clasificación de residuos, emplazadas en el predio que rodea el relleno Norte III (Suárez, Brancoli, Neumann y Ruggeiro, 2011). De acuerdo con uno de nuestros informantes clave, estas plantas fueron construidas con el apoyo provincial y adjudicadas a líderes locales para que incluyeran a las familias humildes que residían en la zona en el circuito formal de la basura. Se les llamó plantas sociales para distinguirlas de las privadas, concesionadas a empresas. Como requisito se exigió la formalización de cooperativas de trabajo, conforme a los principios de economía social. Así fue presentado este proyecto en un documento web de CEAMSE (2006):

En las inmediaciones del Complejo Ambiental Norte III surgieron organizaciones de base, que representan a la gran cantidad de familias humildes que viven de la separación y venta de residuos. La consecuencia fue el ingreso ilegal de personas indigentes al frente de operaciones del relleno que, además de generar diversas dificultades en la disposición final de los residuos, se exponen a contraer infecciones o sufrir cortes o heridas. Y, lo que es más grave, ponen en riesgo sus vidas al desplazarse entre maquinarias de gran porte. Los equipos interdisciplinarios formados por CEAMSE están trabajando para orientar y dar un marco de contención social a estas personas que se encontraban en el mayor desamparo, para que dieran los pasos a fin de constituirse en asociaciones civiles. $Y$ que así sus integrantes encontraran en las plantas sociales su acceso al sistema formal de trabajo.

Este fragmento muestra la caracterización que se efectuaba desde ceAmse del conflicto con los(as) habitantes del área Reconquista, particularmente con relación a las tensiones con las organizaciones barriales constituidas en la zona. La población es caracterizada como "familias humildes que viven de la separación y venta de residuos" que se "encuentran en el mayor desamparo". Las organizaciones de base son responsabilizadas por el ingreso de estas personas al relleno, con los consabidos riesgos que esto importa a su integridad física, sobre todo frente a las "máquinas de gran porte" que operan en ese sitio. Esta caracterización recuerda las denuncias acerca de las circunstancias que rodearon la desaparición de Diego Duarte. Que se efectúe en este contexto da una pauta de la importancia de este conflicto en la puesta en marcha del programa y de la posición de la empresa frente a situaciones como esta.

En este escenario, se pone de relieve la cuestión de la formalidad. Se contraponen las organizaciones de base con las asociaciones civiles que promueve CEAMSE. El "desamparo" en que viven las familias se asocia con su incapacidad de "acceder al sistema formal de trabajo". Así, se instala la contraposición formal-legalseguro versus informal-ilegal-peligroso, presentando a la empresa como agente que promueve el mejoramiento de las condiciones de vida en el barrio a través del programa de plantas sociales. Esto se lograría no sólo facilitando el acceso al "sistema formal de trabajo" de los(as) "indigentes" que acuden al relleno, sino asistiendo a las organizaciones de base a través de sus equipos interdisciplinarios. Sin embargo, la cuestión de la formalidad de las organizaciones es un punto de conflicto mucho más complejo de lo que parece a partir de esta caracterización, como puede verse en el siguiente registro: 
Estamos en una reunión con presidentes de plantas sociales, funcionarios(as) estatales $\mathrm{y}$ autoridades de la CEAMSE celebrada en el Complejo Norte III. Estoy presente en calidad de "especialista amiga" de vu. La primera cuestión que se plantea por parte de un funcionario de CEAMSE es la necesidad de avanzar en la formalización de las cooperativas. Insiste en que "hay que comprometerse", hacer "las cosas en serio" y ser "más prolijos con los papeles". Frente a esta interpelación se pone de pie uno de los presidentes y dice:

"Ustedes saben que para nosotros la cosa no es sencilla, hay compañeros que no tienen ni documento. Nosotros no nos manejamos con libros y asamblea de socios, tenemos otro modo y esto nos obliga a cambiar todo. Nos tenemos que ayudar entre todos, ustedes nos tienen que aguantar un poquito, porque nosotros siempre ayudamos. El único relleno sanitario que hoy no está con fecha de cierre por los ecologistas es este y ustedes saben por qué: acá los ecologistas no tallan porque nosotros defendemos el relleno".

Frente a esto, un funcionario respondió: "Nos consta y nos importa ¿Me oyó? Nos consta y nos importa”. Desde ese momento el tono de la reunión fue más ameno. ${ }^{13}$

Este fragmento permite poner de manifiesto que la cuestión de la formalidad constituye, en última instancia, un conflicto en torno al control de las plantas sociales. La informalidad es constitutiva de la cotidianeidad de los(as) habitantes del área Reconquista en más de un sentido. Muchos(as) no tienen documentos de identidad, no han celebrado jamás un contrato de trabajo, ni tienen constancias escritas de las transacciones de compra-venta de bienes muebles o inmuebles que realizan. Todo se hace "de palabra", incluso los vínculos que se establecen con las organizaciones territoriales. Usualmente, además, estos se constituyen y expresan en función de amistad o afecto, de gratitud o de ayuda. Por eso, someter a la organización a cánones formales impondría otros modos, incompatibles con las prácticas habituales: ¿se puede "dejar afuera" a un compañero que necesita ayuda o merece gratitud porque carece de documento de identidad?

Como se ve en este registro de campo, la situación no es desconocida por los(as) funcionarios(as) de CEAMSE, los(as) cuales saben que no se trata de que los(as) responsables delas plantas sean más o menos prolijos. Del mismo modo, estos(as) están perfectamente al tanto de las preocupaciones empresariales, en par-

13 Registro de campo tomado en una reunión en el Complejo Sanitario Norte III el 10 de enero del 2008. ticular, de las dificultades para abrir nuevos complejos sanitarios en otras zonas.

Esta disputa pone de manifiesto una pugna en torno a la atestación/reconocimiento de las capacidades colectivas de las organizaciones barriales para gestionar las plantas sociales. Dichas capacidades dependen en buena medida del reconocimiento de los(as) funcionarios(as) de CEAMSE y de las agencias financiadoras - estatales en este caso-, que imponen sus condiciones para ello: por ejemplo, formalizar cooperativas. Sin embargo, la posibilidad de imponer tales condiciones también está sujeta a procesos de negociación que no se limitan al programa sino que se inscriben en un proceso mucho más amplio: los históricos enfrentamientos entre vecinos(as) y empresa, pero también sus circunstanciales alianzas frente a adversarios(as) comunes, los(as) ecologistas. Frente a estos(as) se defiende el relleno sanitario, estratégico tanto para la empresa como para los habitantes del área Reconquista.

En reconocimiento de esa ayuda mutua, este dirigente pidió que se los(as) "aguantase un poquito", que se les diese tiempo para formalizar las cooperativas. La respuesta por parte del vocero de CEAmSE fue: "Nos consta y nos importa", reconociendo el carácter estratégico de esta alianza. La eficacia del argumento se trasuntó no sólo en esta respuesta, sino en la inflexión que señaló este comentario en el clima de la reunión. De este modo, se puso de manifiesto una complejidad en los vínculos locales en torno a la gestión de los residuos, incompatible con la distinción entre circuitos formales e informales, la cual supone una prescindencia entre quemeros(as) y empresa que está lejos de observarse en este ámbito.

Esta escena ilustra hasta qué punto la complejidad de las relaciones sociales en torno a CEAMSE y las plantas sociales pone de relieve los límites de los enfoques que utilizamos para abordar los procesos de implementación de programas sociales. Por un lado, porque la mayor parte de las personas vinculadas a este proceso difícilmente han experimentado el salariado, y en cambio, esta política - focalizada, insuficiente, limitada - los(as) habilita para participar en la gestión de los residuos y les permite sentarse frente a frente con las autoridades del relleno a coordinar acciones y estrategias. Por otro, vemos que sería imposible aplicar una separación nítida entre los agentes estatales y los representantes de la sociedad civil, la política y las necesidades. Claramente, lo que se negociaba eran las condiciones de implementación del programa de plantas sociales, 
una política pública. Pero quienes estaban reunidos(as) eran quemeros(as) devenidos(as) en autoridades de las plantas sociales y empleados(as) de Roggio Ambiental que se posicionaban contra otras organizaciones de la sociedad civil a los que nombran como ecologistas, con relación a la gestión de una empresa estatal (CEAMSE) y un problema de agenda pública (el modelo de gestión de residuos) que para unos(as) y otros(as) era una cuestión de subsistencia.

\section{Consolidación de las capacidades colectivas de "Vecinos Unidos" (1999-2004)}

La organización vu fue conformada en 1998 por un grupo de tomadores(as) de tierra que constituyeron un asentamiento sobre un predio fiscal, situado en el área Reconquista, el cual era utilizado hasta entonces como basural y desarmadero de vehículos. El sostenimiento de la toma implicó evitar el desalojo, pero también llevar a cabo actividades comunitarias tales como limpiar y delimitar lotes, demandar chapas y cartones para armar casillas y conseguir y distribuir mercadería. La consecución de estos recursos dependía de donaciones de afluencia irregular, a pesar de lo cual se instaló un comedor que funcionaba cuando "había qué echar a la olla”, según nos contaba una de sus líderes, Eleonora, en una de las entrevistas que realizamos con ella. Esta situación cambió en 1999, cuando la organización se sumó a la Federación de Tierra, Vivienda y Hábitat (FTV). Así nos fue contado por Mauricio, uno de los principales dirigentes de la organización:

Nosotros nos hacemos piqueteros por la FTV y llegamos a la FTV por medio de Barrios de Pie. Ellos, que laburaban más que nada del otro lado del asfalto, nos vinieron a invitar a una reunión para explicarnos que había que sumarse para dar masividad a los cortes y exigir planes y mercadería. Nos vinieron a buscar después de un corte que le hicimos nosotros al CEAMSE por un caso de represión que tuvimos, y que fue todo el barrio y los organismos de derechos humanos y todos decían: “¿Estos de dónde salieron?" Nosotros veníamos muy aceitados por la toma... Ahí nos ofrecieron sumarnos a la FTV, después los de Barrios se pelearon y se fueron y nosotros ya nos quedamos [...] Estuvimos hasta el año pasado [2003] y después empezaron los problemas, por lo del PTA [Partido de los Trabajadores Argentinos], y ya nos abrimos. Pero esos primeros años fueron muy lindos y no sólo aprendimos cómo manejarnos con Provincia y Nación, que fueron aflojando varios puntos, sino que se fueron acercando otros de universidad, los tanos y nosotros fuimos entendiendo cómo es la cosa, que nos necesitamos mutuamente. Ellos necesitan pobres y tienen plata, nosotros somos pobres y necesitamos plata, necesitamos tener un comedor, planes y así hicimos el armado este que usted ve... ${ }^{14}$

Mauricio fue uno de los principales dirigentes de la organización, aunque actualmente se encuentra alejado por conflictos con otros(as) compañeros(as). Formó parte del primer grupo de tomadores de tierra y vive en el asentamiento con su familia, conformada por su esposa, una hija y un hijo, desde 1998. Durante varios años, su trabajo en vu fue su principal actividad, su profesión. Tanto, que en el 2005 se decidió a concluir sus estudios secundarios para comenzar a cursar en el 2007 la Licenciatura en Trabajo Social en la Universidad Nacional de San Martín, según decía, inspirado en su trabajo comunitario en el barrio.

En este breve relato se resaltan varios hitos en la consolidación de vu. Entre ellos se destaca "haberse hecho piqueteros" a partir del vínculo con la Federación de Tierra, Vivienda y Hábitat (FTV), un movimiento de alcance nacional. Sumarse a dicho movimiento les permitió obtener recursos con los que sostener las actividades comunitarias y planes que permitieron "acercar compañeros(as)", quienes pudieron comenzar a "llevarse algo a la casa por participar de las distintas actividades" y, de este modo, "pasar más tiempo en el comedor", como relató Mauricio en otro tramo de esta charla. La gestión de estos recursos consolidó capacidades colectivas específicas, como aprender a relacionarse con los gobiernos nacional y provincial para obtener respuestas favorables a sus demandas.

El desarrollo de estas capacidades se comprende en el marco de la situación sociopolítica de fines de los noventa. Para acceder a planes o mercadería, se requería que los(as) demandantes contaran antes que nada con el reconocimiento público de su "capacidad de movilización". Entonces, para lograr la intervención estatal era necesario crear focos notorios y persistentes de conflicto que además, de ser posible, fueran avalados por grupos o personas prestigiosas. En tal sentido, contar con la presencia de los organismos de derechos

14 Registro de campo de un relato que hizo Mauricio frente a un profesor suizo que se encontraba de visita en el barrio, 7 de octubre del 2004. 
humanos ${ }^{15}$ en una movilización constituía un recurso estratégico. Cuando esto ocurría, era altamente probable que se alcanzara la instancia de negociación, lo cual constituía un primer logro necesario aunque insuficiente.

Una vez alcanzada esta instancia, se negociaba la disponibilidad de recursos. Para ello no bastaba con que los(as) demandantes acreditaran los atributos que definían a la población beneficiaria de los diferentes programas; los(as) líderes, que encaraban las negociaciones en nombre de los(as) manifestantes, debían acordar un cupo - es decir, una cantidad de personas en función de las cuales se calcularían los planes o la mercadería a entregar a la organización-, para lo cual era necesario que acreditaran ser representativos(as). Esto implicaba no sólo que garantizaban que la asistencia llegase a quienes estaba destinada, sino también, y fundamentalmente, que fueran capaces de desactivar el conflicto. Ello daba lugar a lo que, siguiendo a Ricœur (2006), puede caracterizarse como una situación de disputa por las pruebas de calificación que hacían legítima la pretensión, en este caso, de demandar en nombre de los(as) "desocupados(as)".

En tal sentido, resultaba importante la cantidad de personas movilizadas - para poder "pelear el cupo"- pero también los avales políticos que pudieran presentarse a favor de la organización de parte de agrupamientos o personalidades que gozaran de prestigio político. Así, estos avales resultan centrales en tanto acreditaban la representatividad y daban notoriedad al conflicto, como ya hemos señalado. La representatividad tenía entonces varios requisitos: capacidad de movilizar un número significativo de personas, de negociar con los(as) funcionarios(as) un cupo satisfactorio para los(as) movilizados(as), de desactivar la protesta una vez alcanzado el acuerdo y de presentar avales políticos que dieran carácter genuino a la organización. En ningún caso, la organización se bastaba a sí misma para acreditar su representatividad así definida, por eso decimos que la representatividad constituye una capacidad colectiva.

15 En la Argentina, los movimientos por los derechos humanos que han denunciado desde fines de los setenta los crímenes contra la humanidad perpetrados por la última dictadura militar (1976-1983) se conocen como organismos de derechos humanos y gozan de un importante grado de prestigio social dentro y fuera del país. Tal es el caso de las Abuelas y Madres de Plaza de Mayo, pero también del Servicio de Paz y Justicia (Serpaj) conducido por Adolfo Pérez Esquivel, ganador del premio Nobel de la Paz en 1980. En este caso, Mauricio se refería al apoyo de Serpaj, Familiares deDetenidosy Desaparecidos por Razones Políticas y de Madres de Plaza de Mayo Línea Fundadora a las actividades de Vecinos Unidos.
En vistas a esta situación, los(as) dirigentes de FTV comenzaron a construir alianzas en aquellos territorios en los que "no tuvieran trabajo de base propio". Esperaban incorporar agrupamientos que fueran representativos en los términos antes mencionados. Para favorecer su vinculación, se les ofrecía a estos grupos participar del circuito de distribución de recursos de la federación (planes, mercadería, chapas, etc.), se les garantizaba autonomía local para administrarlos y se favorecía la incorporación de sus líderes a las mesas provincial o nacional, a cambio de lo cual se solicitaba acompañar la estrategia política que se definiera en esas mesas (Cross, 2012).

En este proceso se enmarca la invitación de un dirigente de Barrios de Pie, movimiento vinculado por entonces a la FTV, a los(as) líderes de vU. Se consideraba que este agrupamiento reunía las condiciones para ampliar la cobertura de la federación dada su representatividad, acreditada en una movilización a la CEAMSE.

Esta tuvo lugar a fines de 1999 y fue convocada en repudio a la represión sufrida por un grupo de jóvenes quemeros. La movilización consistió en la interrupción del ingreso de camiones transportadores de residuos. Como parte de la estrategia de visibilización convocaron a los medios de comunicación - fundamentalmente noticieros televisivos - y a organizaciones de derechos humanos, en virtud de algunos contactos personales previos de los(as) líderes con Madres de Plaza de Mayo-Línea fundadora y Familiares de Detenidos Desaparecidos por Razones Políticas. La cobertura mediática de la protesta fue sumamente acotada, aunque tuvo amplia repercusión local por el caos vehicular que provocó sobre la Autopista del Buen Ayre.

A partir de esta vinculación, según nos contaba Mauricio, vu pudo contar con una afluencia de recursos que permitió sostener ciertas actividades comunitarias, las cuales facilitaron la consecución de nuevos apoyos, entre los cuales se destacó el de los tanos. Mauricio se refiere en estos términos a VERDE, una oNG italiana que se constituyó a lo largo de varios años en uno de los principales apoyos de vU. El acercamiento de esta ong se produjo a instancias de una de las líderes de Madres de Plaza de Mayo Línea Fundadora, quien, enterada de que verDe gestionaba un programa financiado por la cooperación italiana que estaba orientado a la puesta en marcha de comedores comunitarios, propuso el comedor de vu, dado el buen concepto que tenía de sus líderes. La relación entre VERDE y vU se fue profundizando en el marco de un programa de fortalecimiento del liderazgo 
comunitario al que fueron convocados los principales referentes de la organización: Elenora, Carlos y Mauricio. Según hemos podido relevar, fueron elegidos en tanto respondían "perfectamente al programa", por acreditar "valores democráticos", "independencia de cualquier partido político" y por "vivir en la zona en la que trabajan socialmente".

El crecimiento de la FTV en los años 2001 y 2002 tensionó las relaciones con vu, en tanto los(as) dirigentes se sentían "ninguneados(as)", es decir, no tenidos(as) en cuenta en la medida de sus expectativas. Estas tensiones terminaron en una ruptura en el 2004, cuando se negaron a participar del Partido de los Trabajadores Argentinos (PTA), un partido político creado por la mesa nacional de la FTV para dar apoyo electoral al gobierno por fuera del $\mathrm{PJ}^{16}$ (Cross, 2012). Esta actitud permitió afianzar las alianzas tejidas con otras expresiones COMO VERDE al reafirmarse la autonomía de la organización respecto a los partidos políticos y al gobierno.

Este repaso nos permitió observar cómo entre 1998 y el 2004 la organizaciónse fue consolidando tanto frente a las definiciones de los programas de promoción social (gubernamentales y no gubernamentales) como a los conflictos específicos del territorio. Así, en la implementación local de estos programas se afianzó una trama significativa que permitió la atestación y reconocimiento de las capacidades colectivas de esta asociación. En tal sentido interpreto la provocativa expresión de Mauricio que alude a la "necesidad mutua".

En el 2003, el Gobierno nacional anunció un giro productivista en la política social, como alternativa al asistencialismo de etapas anteriores, consistente en la promoción de la economía social como modo de integrar al trabajo a las poblaciones vulnerables. En la práctica, este giro productivista no sólo involucró la promoción de emprendimientos productivos gestionados como cooperativas, sino también la discontinuación de programas sociales que entregaban planes, tales como el Jefe y Jefa de Hogar Desocupado, que habían resultado clave en el sostenimiento de las actividades comunitarias de las organizaciones territoriales (Cross y Freytes, 2009b). En este escenario, las personas vinculadas a vu se enfrentaron al principal desafío de su historia, la puesta en marcha de la planta social, en un contexto en el que además se complejizó el sostenimiento de las actividades del comedor.

16 PJ es el Partido Justicialista, al cual pertenecía el presidente Néstor Kirchner, a cargo por entonces del ejecutivo.

\section{Los desafíos del proyecto de la planta social (2004-2009)}

Como reconocimiento a su representatividad en el conflicto entre CEAMSE y los(as) quemeros(as), a los(as) líderes de vu les ofrecieron una planta. Esta convocatoria fue recibida en modo ambivalente por parte de los(as) líderes, según hemos registrado. Por un lado, se pensaba que era la oportunidad para dos objetivos muy deseados: uno de ellos, "dar trabajo promoviendo otros valores" como la solidaridad y el respeto, garantizando ingresos dignos y "buenas condiciones"; el otro, conseguir una fuente de recursos propia con la que sostener las actividades comunitarias sin depender "ni del Estado, ni de nadie". Por otro lado, les resultaba inquietante la complejidad involucrada en diseñar y poner en marcha una planta a la medida de las expectativas que depositaban en ella. De partida, esto implicaba buscar financiamiento adicional al ofrecido por el Gobierno de la provincia de Buenos Aires para la construcción de plantas sociales. Por ello, se solicitó apoyo al Ministerio de Desarrollo Social de la Nación (MDS) en el marco de las políticas de promoción de la economía social con un subsidio cercano al millón de pesos.

Este apoyo fue acordado a condición de que se formulase un proyecto que incluyera un presupuesto detallado, un plan de negocios, el aval de una ONG con dos años de experiencia en administración de proyectos financiados con fondos públicos, un programa de capacitación a los(as) futuros(as) trabajadores(as), y se suscribiera el compromiso de conformar una cooperativa de trabajo con ellos(as). La erogación, que fue efectuada en diversas etapas y en un período de varios años, resultaba elevada para los montos que solía otorgar el MDS, considerando además que vu no acreditaba experiencia en proyectos de esa magnitud.

Consultado respecto a esta situación, un alto funcionario gubernamental comentaba que "este proyecto nos interesa mucho, porque vu es una organización de base en serio", "lo que llamamos genuina". Respecto a cuáles eran los aspectos que le conferían tal atributo, señaló "su independencia respecto a cualquier partido" y su "firme vocación de no ser cooptada por el estado".

Resulta llamativo que un funcionario del Estado destaque como virtud, como atributo de genuinidad, justamente, que la organización no fuera cooptable. En esto se ve que el funcionario en cuestión también tenía en mente la oposición entre los intereses del Estado y los intereses de la gente, pero lo que resulta paradójico 
es que para él también el Estado fuera algo ajeno, diferente de él mismo y de sus acciones. Situaciones como estas ponen de manifiesto que el Estado como entidad unificada constituye una metáfora o una ilusión ideológica tan improbable empíricamente como la unificación de la sociedad civil (Abrams, 1988).

En tanto, para vu haber obtenido el respaldo del MDs fue sólo el primer paso. A partir de entonces se hizo necesario cumplimentar una serie de trámites que permitieran no sólo el desembolso del dinero, sino la construcción de la planta. Para afrontar este desafío, se convocó a diferentes organizaciones amigas. ${ }^{17}$ Entre éstas se destacó VERDE, cuyos(as) integrantes pusieron a disposición de este proyecto todos los medios técnicos y políticos a su alcance. A esto debe sumarse el aporte de otras ONG y organismos de ciencia y técnica y el llamado grupo técnico o "mesa chica". Este espacio, de conformación variable, aglutinó a profesionales, militantes y dirigentes políticos que prestaron apoyo en diferentes áreas y en distintos momentos. La diversidad de estas organizaciones amigas y lo inestable de la delimitación de áreas de competencia, exigieron una tarea de coordinación y articulación que muchas veces desbordó a los(as) dirigentes de vu (Cross y Freytes, 2009a).

Por otra parte, y como fue dicho, esta convocatoria fue efectuada en el contexto de la discontinuación de los programas que permitían sostener las actividades comunitarias en el comedor. Esto llevó a buscar nuevas fuentes de financiamiento que permitieran "seguir laburando", lo cual incrementó la cantidad de instituciones interlocutoras y complejizó la gestión de programas. En este marco tuvo lugar una hiperespecialización que dividió a la organización en dos grandes sectores: el proyecto de la planta, motorizado por Eleonora, y las actividades del comedor, coordinadas por Carlos y Mauricio.

Dados los requerimientos del proyecto, Eleonora comenzó a pasar largas jornadas de trabajo en la sede de verde, en la Ciudad de Buenos Aires, a varios kilómetros de su casa. Ocuparse del proyecto de la planta le exigía celebrar reuniones con funcionarios(as), integrantes del equipo técnico y funcionarios(as) de ONG a las que se solicitaba algún tipo de apoyo, las cuales se celebraban algunas veces en Ciudad de Buenos Aires y

17 En particular, la cuestión la elaboración de acuerdos de trabajo y la reflexión en torno a los modos de organizar y gestionar las actividades fueron sostenidas por un equipo de investigación-acción que compartimos con Ada Freytes Frey, Verónica García Allegrone, Florencia Partenio y Alexandre Roig. otras en La Plata, ${ }^{18}$ en ocasiones el mismo día. El acompañamiento de VERDE en estas instancias y los recursos que ponía a disposición eran una condición indispensable para que Eleonora pudiera desempeñar las tareas que tenía encomendadas. En cambio, esto le impedía estar presente como acostumbraba en las actividades cotidianas del comedor.

Por otra parte, Mauricio y Carlos fueron asumiendo cada vez mayor responsabilidad en las actividades comunitarias. Esto involucraba gestión de programas sociales de origen gubernamental y no gubernamentaly hasta de fundaciones privadas - como Fundación Telefónica - que promovían actividades tan diversas como campañas de vacunación, programas de educación sexual, la puesta en marcha de un centro de atención primaria de salud, organización deactividades recreativas y educativas para niños(as) y jóvenes, gestión de documentación de identidad para vecinos(as), promoción de talleres para combatir la violencia de género, distribución de alimentos secos y frescos, entre otras.

Si bien en este ámbito se contaba con el trabajo de muchos(as) compañeros(as), también se incorporaron profesionales amigos(as) de la organización que contribuyeron a atender los diversos frentes. A su vez, la proliferación de fuentes de financiamiento y de actividades para coordinar, llevó a la incorporación de otros(as) amigos(as) convocados(as) para facilitar gestiones legales y administrativas como la rendición de fondos, hacer los libros de la asociación civil y las cooperativas creadas, celebrar contratos y buscar financiamiento para continuarlas actividades cuando se agotaba el vigente, por enumerar algunos casos.

Después de un tiempo de estar a cargo del proyecto de la planta, y justo cuando se avizoraba su inauguración, Eleonora planteó que se sentía "afuera de todo" y quiso volver al comedor. Mauricio y Carlos, entonces, se hicieron cargo de la planta en la fase final de implementación del proyecto. Luego de cinco años, en marzo del 2009, la planta comenzó a operar en un galpón capaz de albergar a más de cien trabajadores(as) en tres turnos y con equipamiento para procesar varias toneladas de basura domiciliaria por día. En ese contexto, el proceso de desarticulación que había comenzado a plantearse en el 2004 se profundizó. Algunas de las personas que hacían trabajo comunitario se fueron a la planta, mientras que otras fueron asignadas a dar

\footnotetext{
18 La ciudad de La Plata es la capital de la provincia de Buenos Aires y se encuentra a $52 \mathrm{~km}$ de la Ciudad de Buenos Aires y a $94 \mathrm{~km}$ del área Reconquista, donde está la casa de Eleonora.
} 
continuidad a las tareas del Comedor. Estos cambios trajeron aparejados conflictos, algunos de los cuales se expresan en este fragmento: ${ }^{19}$

El comedor cambió mucho, ya no es como era antes. Desde que se fueron los muchachos [Mauricio y Carlos], los compañeros estamos medio perdidos... A veces aparecen, porque ahora se la pasan en Capital, y te traen a uno y te dicen: "Acá el muchacho va a trabajar con vos, mostrale y fijate si las reuniones las pueden hacer en otro horario que él pueda venir"...Es amigo de la organización, te dicen, pero yo no debo ser de la organización porque amigo mío no es... Después, que te decían que la planta era de todos y a mí no me dejan ni ir a ver. Ahora viene cualquier pibe de la universidad y puede ir. ¿Por qué no puedo saber? ¿ No era de todos? ¿Y ahora qué pasa? Yo a veces no digo nada por no pelear, pero, $\grave{i}$ vos te parece?

Celeste es una mujer que se vinculó a vu en el 2004, cuando se estaba diseñando el proyecto de la planta social. Eso hace que se sienta más cómoda con los "muchachos", dado que por entonces Eleonora pasaba largas jornadas en la sede de verde. Cuando la planta comenzó a operar, quiso ir a trabajar allí, pero le pidieron que se quedara en el comedor y así lo hizo. A poco de ponerse en funcionamiento la planta, comentaba lo incómoda que se sentía por no saber qué estaba pasando en la planta. No la "dejaban ir", no le "querían contar" lo que pasaba, y en tal sentido se sentía despojada respecto a ese proyecto y también segregada respecto al grupo con el que se hallaba más cómoda.

En este fragmento se subraya la distinción entre compañeros(as) y amigos(as). Los(as) primeros(as) son quienes, como ella, viven en el barrio y forman parte de la organización de pleno derecho; en cambio, se denomina amigo(a) a quien ocasionalmente brinda(mos) algún tipo de apoyo a la organización. La denominación de amigo(a) de la organización, si bien constituye una apelación afectiva, también señala un límite, una exterioridad respecto al vínculo pleno que entablan los(as) compañeros(as).

Interpreto que no es la presencia de $\operatorname{los}($ as) amigos(as) lo que molesta a nuestra interlocutora, dado que ambas figuras han coexistido casi desde el inicio de la organización, sino lo que ella percibía como un notorio cambio en el modo de gestionar los vínculos: los/as compañeros(as), quienes llevaban cotidianamente ade-

19 Registro de campo de las impresiones de Celeste referentes al trabajo en el comedor, mayo del 2009. lante las tareas, debían adaptarse a las posibilidades de los(as) amigos(as) y no a la inversa. Este cambio era vivido por ella no sólo como una desvalorización del trabajo de los(as) compañeros(as), sino como reafirmación de la distancia respecto a los(as) dirigentes. Al decir que "se la pasan en Capital", ${ }^{20}$ señala una distancia que está mucho más allá de lo geográfico.

Los problemas de articulación y coordinación son característicos de espacios en los que hay un alto grado de informalidad, indispensable por otra parte para poder gestionar con los escasos recursos disponibles, la multiplicidad de cuestiones con las que deben lidiar a diario. Pero, considerando la importancia que se le da a los vínculos cara a cara en este tipo de organización, este tipo de distanciamiento supone una amenaza importante para la integración de la organización.

En todo caso, lo que muestra este párrafo es el proceso de profesionalización de la organización en cuanto a a) la división de tareas entre los(as) integrantes, b) el tiempo que cada vez una cantidad mayor de ellos(as) le dedicaba a las diferentes tareas comunitarias de la organización y c) la necesidad de convocar a estos(as) "amigos (as)" con diferentes especialidades, cuya colaboración pasó a ser cada vez más importante para el desarrollo de las tareas que se les imponían. Para quienes estaban trabajando en la planta, tampoco las cosas resultaban sencillas como puede verse en lo que sigue: ${ }^{21}$

Acá tenemos un gran problema entre los que son los históricos y los nuevos compañeros, porque la cosa cambió mucho. Antes se sabía que los que estaban en la lucha iban a recibir del cupo. La planta se ha conseguido por ser una organización luchadora, que ha dado pelea a la policía, al CEAMSE, nadie regala nada... Pero ahora es distinto, porque acá lo que hay para repartir es lo que se gana vendiendo, entonces tenés que saber, sacar producción... La historia que vos tenés en la organización, al compañero nuevo no le importa, si uno no sirve, ya te dicen que lo tenés que sacar, y ese que me dice que lo tengo que sacar, ¿dónde estaba mientras cortábamos la autopista? Hacía changas para llenarse el buche él, no entiende la lucha de nosotros... Pero ceAmse si no sacás producción te dice que te saca la planta, o va a poner esas plantas nuevas que es todo automático y volvemos

20 "Capital", abreviando "Capital Federal", es el modo en que los/as habitantes del conurbano se refieren a la Ciudad de Buenos Aires, que es la capital del país y se encuentra a unos $23 \mathrm{~km}$ del área Reconquista.

21 Registro de campo de las apreciaciones de Rodolfo, encargado de la planta, diciembre de 2009. 
a lo mismo de antes, a morirte en La Quema y si no te ponés firme nadie va a laburar porque tampoco es lindo meter la mano en la basura, pero después te escrachan que sos autoritario... A veces, te digo la verdad, pienso que estábamos mejor antes.

Rodolfo se vinculó a la organización allá por el 2002 cuando se quedó sin trabajo en el depósito de alimentos en el que trabajaba "en negro". En un primer momento, buscaba ser incorporado al cupo de la organización para tener un plan. Una vez que lo consiguió se fue enganchando, comprometiendo con distintas actividades comunitarias, y se convirtió en uno de los líderes de la organización.

Este tramo de la entrevista muestra otra importante fuente de tensión generada por la apertura de la planta y del proceso de profesionalización de vu: los conflictos entre los(as) históricos(as) de la organización, como él, y los(as) nuevos(as) compañeros(as), los(as) que se sumaron al comenzar a trabajar en la planta. Los(as) primeros(as) tienen entre sus credenciales el haber participado en las diversas luchas en las que estuvo involucrada vu, las cuales les valieron -por cierto- la posibilidad de gestionar la planta. Pero desde el momento en que el retiro que cada trabajador(a) obtiene al terminar la semana depende de la cantidad de materiales que se han clasificado y vendido, entonces lo que empieza a cobrar valores es saber, por ejemplo, distinguir adecuadamente los tipos de material y sacar producción. Sin embargo, estas diferentes formas de acreditar derechos no siempre son compatibles y puede darse la situación que los nuevos compañeros pidan que se saquea un compañero de años, de los llamados históricos, porque tiene baja productividad. Ahora bien, ¿tiene derecho quien no ha participado de las luchas precedentes a imponer condiciones a los que han luchado sin obtener durante años más recompensa que la promesa de un trabajo menos arriesgado que ir a La Quema? Para Rodolfo la respuesta no está tan clara.

$Y$ es que, precisamente, la planta exige el desarrollo de nuevas capacidades colectivas, que podemos designar como garantizar la sustentabilidad del emprendimiento. Esta sustentabilidad tiene diversas dimensiones: generar puestos de trabajo razonablemente remunerados, sostener las actividades comunitarias que dan sentido a la organización, ser eficaces en la reducción de los volúmenes que van a ser enterrados $y$, último pero más complicado, hacerlo sin reproducir las prácticas autoritarias de las empresas privadas. Si no fuera posible acreditar estas capacidades, existe el riesgo con- creto de que la planta sea asignada a otra organización o sea cerrada y reemplazada por sistemas más sofisticados que pueden procesar más volumen con menos trabajo humano, como el caso de la planta inaugurada por el Gobierno de la Ciudad durante el 2013, lo cual implicaría que muchos(as) de los(as) hoy trabajadores(as) volvieran a ser quemeros(as).

Sin embargo, si para cumplir este objetivo se olvidan los objetivos comunitarios, estaríamos frente al riesgo cierto de que planta y comedor se autonomicen, y en ese caso todo el esfuerzo económico y político de tantos años podría quedar reducido a la construcción de una planta que ofrece puestos precarios a unas cien personas. En esto se refuerza nuevamente nuestra tesis acerca de que las organizaciones territoriales son agentes clave en el proceso de implementación de estos programas porque son la condición de posibilidad de dar un sentido colectivoa estos esfuerzos. No obstante, su mera intervención no puede garantizar estos resultados porque muchas veces el desarrollo de las capacidades colectivas requeridas suele quedar librado al azar de las relaciones que puedan/quieran entablar los(as) líderes y los recursos extra que sean capaces de movilizar, equipos técnicos, amigos(as) que colaboren, fuentes de financiamiento para actividades específicas. Además, la posibilidad de poder encontrar, aunque sea provisoriamente, una respuesta acerca de cómo es posible compatibilizar la lucha con la obtención de resultados económicos, se vuelve todavía más difícil cuando ni desde la propia academia nos animamos a pensar que sean objetivos compatibles.

\section{Reflexiones finales}

La proliferación de organizaciones territoriales constituye uno de los emergentes más notables de los cambios en nuestra sociedad a lo largo de las últimas décadas en lo que se refiere al rol asumido por el Estado, pero también a las diversas estrategias delucha y resistencia frente a los procesos de segregación social que impone el actual modelo de acumulación. Dar cuenta de la complejidad de este proceso nos exige prestar mucha atención para no quedar atrapados en el pensamiento hegemónico: toda vez que pensamos al Estado escindido de la sociedad, la política separada de la economía, a los sectores populares como desafiliados(as), menospreciando toda expresión de organización y movilización popular, reproducimos la lógica de la focalización que señala a los(as) pobres como incapaces. 
Por eso trabajamos desde el concepto de capacidades colectivas, lo que nos permite vincular padecimientos singulares, conflictos locales, políticas sociales y gestión de recursos al considerar las tramas de relaciones que se constituyen en los procesos de implementación local de políticas sociales. Estas tramas, que han sido condición de posibilidad de la implementación de los programas, han quedado libradas a la contingencia, dado que no son tenidas en cuenta como constitutivas del proceso. De hecho, en algunos enfoques se las considera fuentes de lazos espurios, lo cual seguramente ha redundado en derroches de energía y recursos, que sería importante evitar y corregir de cara al futuro. Pero, ¿cómo podremos hacerlo si ni siquiera podemos estudiarlo? ¿Cómo podríamos comprender lo que ha pasado si no podemos captar estos procesos en su riqueza y complejidad? ¿Cómo vamos a capitalizar lo aprendido hasta aquí si no podemos dar cuenta de ese aprendizaje?

En este sentido, un primer punto que surge del análisis es la necesidad de insistir en desnaturalizar la frontera entre sociedad civil y Estado. La implementación de programas como los que analizamos muestra que agentes estatales y beneficiarios(as) de ningún modo pueden pensarse como conglomerados homogéneos y aislados entre sí. En cuanto a la homogeneidad, baste recordar que fue un funcionario que renegaba de la cooptación estatal el que apostó por el financiamiento de la planta, fue una ONG italiana la que logró articular al equipo técnico que impulsó el proyecto de ese emprendimiento, en el que finalmente trabajan personas que no necesariamente participaron de los conflictos previos junto con otros(as) que participaron de la lucha. De hecho, muchos(as) se definen como desocupados(as), pero han tenido sus primeras experiencias laborales colectivas en estos emprendimientos. Y en lo referido al aislamiento, vimos que la organización no hubiera podido erigirse en administradora de los programas si esa capacidad no le hubiera sido reconocida por las instituciones financiadoras, los propio destinatarios(as) y ese conglomerado difuso de amigos(as) que hacen su aporte técnico y profesional. Las reglas para ese reconocimiento no son estáticas, ni están aisladas de la definición formal de los programas, pero tampoco pueden vislumbrarse desde lo escrito en el papel.

Un segundo punto es que financiadores(as) y beneficiarios(as) no pueden ser los únicos actores sobre los que versen las investigaciones. ¿Qué hubiera sido del comedor sin el acompañamiento de los organismos de derechos humanos? ¿Qué hubiera sido del proyecto de la planta sin el aporte técnico de VERDE? Por eso consideramos que es más sugerente pensar las políticas sociales como ámbito de producción de lazos sociales, que como mero mecanismo de distribución de recursos.

Finalmente, el análisis de esta experiencia muestra que la productividad política de estos procesos no debiera ser subvalorada. Como vimos, en todos estos años las personas vinculadas a vu fueron capaces de desarrollar prácticas de gestión de recursos de fuentes muy variadas, para lo cual desarrollaron diversas capacidades individuales y colectivas que, por un lado, implicaron la trasferencia de hecho de muchas responsabilidades administrativas y costos de gestión desdeagencias gubernamentales y no gubernamentales. No obstante, lejos de profundizar la vulnerabilidad de sus integrantes, estas prácticas les permitieron convertirse en interlocutores(as) autorizados(as) de funcionarios de instituciones públicas y privadas, especialistas y profesionales de diversos ámbitos y posicionarse como administradores(as) de recursos frente a los(as) demás habitantes del barrio. Por otra parte, para las personas vinculadas a estos procesos, para muchas de las cuales estas experiencias fueron las primeras ocasiones en las que se sintieron reconocidas como sujetos de derecho, el aprendizaje acerca, no sólo de qué pueden reclamar, sino de cómo pueden hacerlo, significó un paso adelante en su integración política y social. Esto no implica sostener que las políticas focalizadas sean eficaces por sí mismas en función de (re)construir los lazos sociales de los sectores más empobrecidos, sino subrayar la capacidad creativa de estos sectores, la productividad política de sus esfuerzos de organización colectiva, que no podremos aprehender oponiendo política y necesidad, ni pensando a los sectores populares desde categorías como la de desafiliación.

Al pensar al Estado como agente de integración social, tendemos a pensar a los(as) beneficiarios(as) no sólo como un conglomerado homogéneo, que no son, sino pasivo, que tampoco. Mirando más de cerca, en cambio, podemos ver que a lo largo de estos más de diez años en la implementación de políticas focalizadas se han configurado tramas que no se dejan reducir a la separación tajante entre sociedad civil y Estado, que no se pueden aprehender si pensamos la implementación de políticas sociales como una relación unidireccional y lineal entre Estado y población destinataria.

En ese escenario, las organizaciones territoriales se han convertido en un agente central no sólo por su capacidad de gestionar estas tramas, sino por los sen- 
tidos que ayudan a crear alrededor de estos procesos. Como vimos, es la existencia de una organización lo que permite dar un sentido colectivo a los padecimientos singulares, de los(as) quemeros(as), los(as) desocupados(as), los(as) pobres, que de ese modo se sienten habilitados(as) a exigir soluciones a problemas que el mercado no puede ver más que como déficits singulares. Y al hacerlo colectivamente, luchando, lo que se obtiene es a la vez de todos(as) pero de nadie en particular, y se vislumbra la existencia de un interés que está por encima de la propia conveniencia y voluntad. Y eso es nada más y nada menos que política.

\section{Referencias}

Abrams, P. (1988). Notes on the Difficulty of Studying the State (1977). En Journal of Historical Sociology, 1(1), 58-89.

Álvarez, N. R. (2009). La basura en clave de lucha de relaciones de poder en el proceso de cierre de una descarga clandestina en José León Suárez. Questión, 1(24). Recuperado de: http://www.perio.unlp.edu.ar/ojs/index. php/question/article/view/886/787

Álvarez, L. S (2000). Políticas de desarrollo social, transformaciones y paradojas. En Hintze, S. (Comp.). Estado y sociedad. Las políticas sociales en los umbrales del siglo XXI (pp. 95-110). Buenos Aires: Eudeba.

Ander-Egg, E. (1990). Repensando la investigación acción participativa. Comentarios, críticas y sugerencias. Buenos Aires: Lumen-Hvmanitas

Andrenacci, L. y Repetto, F. (2006). Universalismo, ciudadanía y Estado en la política social latinoamericana. Washington, DC: Instituto Interamericano para el Desarrollo Social (INDES). Recuperado de: http://www.ciesu. edu.uy/universalismo/Andrenacci.pdf

Baker. C. S. (2005). An understanding of poverty from those who are poor. Action Research, 3(1), 9-31.

Candia, J. (1998). Exclusión y pobreza: la focalización de las políticas sociales. Estudios políticos, (17), 97-105. Recuperado de: http://revistas.unam.mx/index.php/rep/ article/viewFile/37184/33768

Carenzo, S. y Míguez P. (2010). De la atomización al asociativismo: reflexiones en torno a los sentidos de la autogestión en experiencias asociativas desarrolladas por cartoneros. Maguaré, (24), 233-263.

Castel, R. (1997). La metamorfosis de la cuestión social. Una crónica del salariado. Buenos Aires: Paidós.

CEAmse. (2006). Coordinación Ecológica Area Metropolitana Sociedad del Estado. Noticias CEAMSE 11(21), 6-15, Recuperado de: http://www.ceamse.gov.ar/revista/revista21/ N_21_nota1.pdf
Cisterna. C. F. (2005). Categorización y triangulación como procesos de validación del conocimiento en investigación cualitativa. Theoria, 14(1), 61-71.

Cross, C. (2012). Movimientos sociales y poder político: la politicidad de la acción colectiva como eje de debate entre dirigentes sociales de la FTv/PTA de Argentina. Elecciones, 12, 71-98.

Cross, C. (2013, diciembre). Vulnerabilidad social e inempleabilidad: reflexiones a partir del estudio de un programa de reciclado de residuos sólidos urbanos. Trabajo y Sociedad, 21, 475-494.

Cross, C. y Freytes, F. A. (2009a). The Social and Ecological Dimensions of a Decentralisation Process: Participation by Social Movements in the Sustainable Management of Urban Solid Waste in Buenos Aires. En U. Geiser y S. Rist (Eds.), Decentralisation Meets Local Complexity: Local Struggles, State Decentralisation and Access to Natural Resources in South Asia and Latin America (pp. 93-125). Berna: Geographia Bernesia.

Cross, C. y Freytes, F. A. (2009b). Políticas sociales como límite y como herramienta: reflexiones a partir de experiencias de gestión de dirigentes y referentes piqueteros/ as en el período 2001-2007. El Príncipe, 1, 75-98.

Danani, C. (2013). El sistema de protección social argentino entre 2002 y 2013: buscando el modelo que nunca tuvo. Revista Uruguaya de Ciencia Política, (22), 145-169.

Filgueira, F. (2014). Los regímenes de bienestar en el ocaso de la modernización conservadora: Posibilidades y límites de la ciudadanía social en América Latina. Revista Uruguaya de Ciencia Política, (22 N. Esp), 10-27.

Freytes, F. A. y Cross, C. (2007). Movimientos Piqueteros: alcances de su construcción política. Política y Cultura, 27, 121-141.

Freytes, F. A. y Cross, C. (2011). Overcoming Poor Youth Stigmatization and Invisibility Through Art: A Participatory Action Research Experience in Greater Buenos Aires. Action Research, 9, 65-82.

Freytes, F. A., Menéndez, D., García, N., Allegrone, V. y Cross, C. (2007). Tendiendo puentes: reflexiones sobre la colaboración de un equipo universitario en un proyecto de construcción de una planta de selección de residuos. En M. Barrientos y C. Huarte (Comp.), Políticas sociales de desarrollo y ciudadanía: reflexiones desde el sur latinoamericano (pp. 103-120). Buenos Aires: UNDP.

Glaser, B. y Strauss, A. (1967). The discovery of grounded theory. Strategies for qualitative research. New York: Aldine Publishing Company.

Grassi, E. (2003). El asistencialismo en el estado neoliberal. La experiencia argentina de la década del 90. e-Latina, 1(4), 27-48. Recuperado de: http://iigg.fsoc.uba.ar/artic02 
Gustavsen, B. (2003). News form of knowledge production and the role of action research. Action Research, 1(2), 153-164.

Hintze, S.(2007). Políticas sociales argentinas en el cambio de siglo. Conjeturas sobre lo posible. Buenos Aires: Espacio Editorial.

Kenworthy, L. (2011). Targeting May Not Be So Bad.Oxford: Oxford University Press.

Kerstenetzky, C. (2006). Políticas Sociais: focalização ou universalização? Economia Política, 26(4),564-574.

Leuboult, B., Fischer, K. y Saha, 1. (2014). Are targeting and universalism complementary or competing paradigms in social policy? Insights from Brazil, India and South Africa. International Journal of Labour Research, 6(1), 76-93.

Maldovan, J. (2011). La asociatividad como estrategia de acción colectiva: el caso de las cooperativas de cartoneros en Buenos Aires. Otra Economía, 5(9), 139-151. doi: 10.4013/otra.2011.59.03.

Maxwell, J. (1996). Qualitative Research Design. An interactive approach approach. Thousand Oaks, CA: Sage Publications.

Mc Neill, D. (2006). The diffusion of ideas in Development Theory and Policy. Global Social Policy, 6(3), 334-354.

Merklen, D. (2000). Vivir en los márgenes: la lógica del cazador. Notas sobre la sociabilidad y cultura en los asentamientos del Gran Buenos Aires hacia fines de los 90. En Svampa, M. (Ed.). Desde abajo: La transformación de las identidades sociales (pp. 81-119). Buenos Aires: Biblos.

Merklen, D. (2005). Pobres Ciudadanos: Las clases populares en la era democrática: (Argentina 1983-2003). Rosario: Gorla.

Raymer, A. (2009). Big returns for a little more investment: Mapping theory in emergent research. Action Research, 7(1), 49-68.

Ricœur, P.( 2006). Caminos del reconocimiento. Tres estudios. México: FCE.
Ricœur, P. (1996). Sí mismo como otro. Madrid: Siglo xxI Editores.

Ricœur, P. (2000). Narratividad, fenomenología y hermenéutica. Anàlisi, (25), 189-207.

Schuster, F. (2002). Filosofía y Métodos en las ciencias sociales. Buenos Aires: Manantial.

Searle, J. (2006). Social Ontology: Some basic principles. Anthropological Theory, 6(1), 12-29. doi:10.1177/ 1463499606061731.

Secretaría de Salud de la Municipalidad de Gral. San Martín. (2007). Hospital 2010. Plan Estratégico. Argentina: Autor.

Sen, A. (2000). Development as freedom. New York: Alfred A Knopf Inc.

Shammah, C (2007). Territorio basura. En $1^{\mathrm{er} F o r o ~ y ~ C o n-~}$ greso Internacional de Políticas de Reciclado en Grandes Urbes. Congreso llevado a cabo en Buenos Aires, Argentina. Recuperado de: http://www.ides.org.ar/ shared/practicasdeoficio/2007_nro1/07_DCSDossier. Palabras.Clave_Cinthia.Shammah.pdf

Snow, D., Morill, C. y Anderson, L. (2003). Elaborating analytic ethnography: Linking fieldwork and theory. Ethnography, 4(2), 181-200.

Suárez, F., Brancoli, D., Neumann, M. y Ruggiero, C. (2011). Del barrio al relleno, del relleno a las Plantas Sociales. Recuperado de: https://www.e-science.unicamp. $\mathrm{br} /$ support/admin/publicacoes/ documentos/publicacao_5043_plantas_sociales.pdf

Taylor, S. y Robert B.(1996). Introducción a los métodos cualitativos de investigación. Barcelona: Paidós.

Vasilachis de Gialdino, I. (2009). Los fundamentos ontológicos y epistemológicos de la investigación cualitativao. FQS, 10(2). Recuperado de http://www.qualitative-research.net/index.php/fqs/article/view/1299/2778

Vilas, C. (1997). La reforma del estado como cuestión política. Política y Cultura, (8), 147-185. 